\title{
PERBANDINGAN DAN ANALISIS UNTUK ALGORITMA DETEKSI TEPI PADA JARINGAN SARAF TIRUAN
}

\author{
Gabriel Indra Widi Tamtama
}

Universitas Kristen Duta Wacana

Jl. Dr. Wahidin Sudirohusodo No.5-26, Kotabaru, Jebus, Kota Yogyakarta, Daerah Istimewa Yogyakarta 55224 gabrielindra.giwt@gmail.com

\begin{abstract}
Abstrak - Seiring dengan kemajuan komputer, teknik pemrosesan gambar menjadi berkembang dengan pesat. Segmentasi citra adalah salah satu bidang dalam pemrosesan gambar untuk mengenali suatu obyek gambar. Salah satu segmentasi citra adalah ekstraksi fitur tepi (edge detection) dan kurva dari sebuah gambar. Paper ini akan memberikan informasi mengenai studi perbandingan teknik deteksi tepi dengan berbagai metode. Perbandingan metode meliputi bentuk objek yang akan dikenali tepinya, tingkat akurasi gambar, waktu eksekusi program dan output yang diberikan. Ada tujuh algoritma deteksi tepi yang digunakan, algoritma ini terbagi menjadi dua yaitu orde satu meliputi Sobel, Prewit, Robert, Isotropic, dan Compas. Sedangkan orde dua meliputi Canny dan Laplacian. Hasil percobaan dievaluasi berdasarkan nilai kemiripan dengan citra asli dengan pendekatan MSE dan PSNR. Hasil evaluasi menunjukkan bahwa dari 3 citra yang di ujicoba metode canny mendapatkan 2 hasil terbaik dari ketiga citra dengan nilai MSE \& PSNR pada citra 1 dan 2 sebesar 246,95 \& 3,67 dB dan 249,16 \& 2,55 dB.
\end{abstract}

Kata Kunci- jaringan saraf tiruan, deteksi tepi, pemrosesan gambar, perbandingan algoritma, MSE, PSNR

Abstract - As computers progressed, image processing techniques developed rapidly. Image segmentation is one area in image processing to recognize an image object. One image segmentation is the extraction of edge features and curves from an image. This paper will provide information on comparative studies of edge detection techniques with various methods. Method comparisons include the shape of the object to be recognized by the edges, the level of accuracy of the image, the time of program execution and the given output. There are seven edge detection algorithms used, this algorithm is divided into two, namely first order includes Sobel, Prewit, Robert, Isotropic, and Compas. While the second order includes Canny and Laplacian. The experimental results were evaluated based on the similarity value with the original image with MSE and PSNR approaches. The evaluation results show that from the 3 images tested by the canny method, the best results from the three images with MSE \& PSNR values in images 1 and 2 were $246.95 \& 3.67 \mathrm{~dB}$ and $249.16 \& 2.55 \mathrm{~dB}$.

Keywords - artificial neural networks, edge detection, image processing, algorithm comparison, MSE, PSNR

\section{PENDAHULUAN}

Perkembangan teknologi atau era teknologi informasi saat ini sudah tidak dapat lagi dipisahkan dari multimedia, data atau informasi tidak hanya dalam bentuk teks saja, melainkan dalam bentuk gambar, audio dan video [1]. Gambar atau citra merupakan bentuk informasi visual, selain itu karakteristik citra tidak dimiliki oleh data teks, citra juga kaya akan informasi [2]. Ekstraksi fitur merupakan suatu pengambilan ciri fitur dari suatu bentuk objek yang akan menghasilkan nilai dan akan dianalisis, yaitu dengan menghitung jumlah titik atau pixels. Proses pengecekan ini dilakukan dari berbagai arah atau tracking yaitu vertikal, horizontal, diagonal kanan dan diagonal kiri [3]. Oleh karena itu agar komputer dapat mengenali citra proses yang dilakukan yaitu digitalisasi, yang mana proses ini disebut pemindaian, pengambilan sampel dan kuantitas [4]. Selain itu Spiking Neural Network (SNN) juga memiliki kemampuan komputasi yang kuat cocok untuk pemrosesan visual seperti pengenalan pola dan segmentasi gambar [5].

Deteksi tepi merupakan alat mendasar yang digunakan dalam sebagian besar aplikasi pemrosesan gambar atau citra untuk memperoleh informasi dari bingkai untuk ekstraksi fitur dan objek segmentasi [6]. Tepi adalah batas antara objek dan latar belakang dan menunjukkan batas antara objek yang tumpang tindih. Tepi menunjukkan batas objek dan digunakan untuk proses segmentasi objek [7]. Umumnya, deteksi tepi menggunakan 2 macam detektor, yaitu detektor baris Hy dan detektor kolom Hx. Deteksi tepi dapat dibagi menjadi dua golongan. Golongan pertama disebut deteksi tepi orde pertama, yang bekerja dengan menggunakan turunan atau diferensial orde pertama. Termasuk kelompok ini adalah operator Robert's, Prewitt, dan Sobel sedangkan Golongan kedua dinamakan deteksi tepi orde kedua, yang 
menggunakan turunan orde kedua. Contoh yang termasuk kelompok ini adalah Laplacian of Gaussian (LoG) [8].

Pada penelitian ini akan dianalisis perbandingan dan analisis untuk algoritma deteksi tepi menggunakan operator Sobel, prewitt, robert, Canny, Laplacian, Isotropic, dan Compas (kirsch). Metode-metode tersebut akan diujicobakan ke beberapa citra yang berbeda [9].

Pada pengukuran tingkat kemiripan dua buah citra ada 3 parameter yang paling sering digunakan untuk membandingkan hasil pengolahan citra dengan citra aslinya, yaitu menggunakan MSE (Mean Square Error), RMSE (Root Mean Squared Error) dan PSNR (Peak Signal to Noise Ratio) [10][11]. MSE dan RMSE tidak memiliki satuan sedangkan satuan dari PSNR adalah desibel. Jadi jika kedua citra semakin mirip maka nilai MSE dan RMSE akan semakin mendekati nol, sedangkan untuk PNSR sendiri jika dua buah citra bisa dikatakan mempunyai kemiripan yang rendah nilai PSNR nya dibawah 30dB [12].

\section{TINJAUAN PUSTAKA}

Penelitian serupa yang berkaitan dengan perbandingan edge detection pernah dilakukan beberapa peneliti sebelumnya. Wang Luo, melakukan penelitian tentang perbandingan edge detection dengan gambar koloni. Metode yang digunakan adalah Roberts Cross, Sobel Operator, Prewitt operator, Canny, dan Genetic Algorithms. Metode Canny menghasilkan kinerja terbaik secara visual maupun kuantitatif berdasarkan ukuran seperti jarak rata-rata, peta tepi kesalahan, dan rasio noise. Sedangkan metode GA menghasilkan keluaran yang efektif untuk deteksi tepi untuk gambar koloni dengan acak karena tidak menggunakan data piksel melainkan fitur tekstur lokal, namun memakan running time yang cukup lama [13].

Penelitian mengenai survey teknik segmentasi citra dilakukan pula oleh Zaitoun-Aqel. Dalam penelitian tersebut, peneliti melakukan survey terhadap metodemetode pengolahan citra untuk deteksi tepi. Metode yang dibandingkan untuk edge detection yaitu Roberts, Prewitt, dan Sobel detection. Sedangkan untuk pendekatan secara komputerisasi menggunakan Fuzzy Logic, Genetic Algorithm, dan Neural Network [14].

Shrivakshan, dalam penelitiannya meneliti mengenai berbagai teknik deteksi tepi yang digunakan dalam pemrosesan gambar. Metode yang digunakan yaitu Roberts, Sobel, Prewitt, Laplacian, dan Canny. Implementasi program menggunakan Matlab untuk penggunaan gambar Shark Fish Classification. Penelitian ini juga membahas kelebihan dan kekurangan dari setiap metode yang digunakan [15].

Penelitian yang berkaitan dengan evaluasi performa metode deteksi gambar dilakukan oleh Juneja dkk. Hasil yang didapat setelah membandingkan performa dari algoritma Sobel,
Prewitt, Robert's cross, Laplacian of Gaussian, dan Canny, diperoleh bahwa untuk mendeteksi tepi pada gambar spasial, algoritma Canny lebih baik di hampir semua scenario yang diuji coba [16].

Keefektifan dari deteksi tepi menjadi perhatian khusus bagi peneliti yang akan melakukan penelitian terkait. Keefektifan sangat penting untuk menunjang performa dan kinerja komputer vision. Wharton dkk membahas keefektifan deteksi tepi dengan membandingkan beberapa metode seperti Sobel dan Canny [17].

Deteksi tepi yang konvensional mengalami perkembangan dengan proses hybrid image threshold yang menggabungkan metode P-tile dengan deteksi tepi. Penelitian ini dilakukan oleh Samopa dan Asano dan menghasilkan ekstraksi bentuk objek yang lebih akurat dibanding metode konvensional biasa [18].

Qiang Ji dkk meneliti keefesien dari deteksi tepi dan mengevaluasi kinerja secara kuantitatif. [19]. Penelitian ini memperkenalkan prosedur rekursif untuk menghitung parameter segi kubus untuk deteksi tepi secara efisien.

Sharifi dkk memperkenalkan klasifikasi baru dari algoritma deteksi tepi yang paling penting dan umum digunakan untuk memudahkan pemahaman mengenai deteksi tepi. Metode yang paling sering digunakan yaitu ISEF, Canny, Marr-Hildreth, Sobel, Kirsch, Lapla1 dan Lapla 2 [20].

Berdasarkan studi literature yang dilakukan, penelitian ini mengulas mengenai perbandingan metode untuk deteksi tepi dengan beberapa pendekatan yang berbeda. Beberapa kategori digunakan untuk menguji performa dari setiap metode deteksi tepi. Kategori-kategori tersebut antara lain bentuk objek, warna, waktu eksekusi, ukuran pixel dan ada atau tidaknya noise dalam suatu citra. Tujuan penelitian ini untuk mencari tahu metode deteksi tepi yang cocok digunakan dalam suatu kasus tertentu dan menjelaskan kepada pembaca mengenai metodemetode deteksi tepi. Tolok ukur perbandingan dengan memperhitungkan nilai Signal to Noise Ratio (SNR) dan Mean Square Error (MSE) pada citra asli.

\section{METODOLOGI PENELITIAN}

Pada tahap ini akan dilakukan beberapa tahapan untuk melakukan edge detection. Setiap gambar akan melalui semua algoritma edge detection dan hasilnya akan dibandingkan berdasarkan MSE, dan PSNR [12]. Alur penelitian dapat dilihat pada gambar 1 di bawah ini: 
Page $\mid 69$

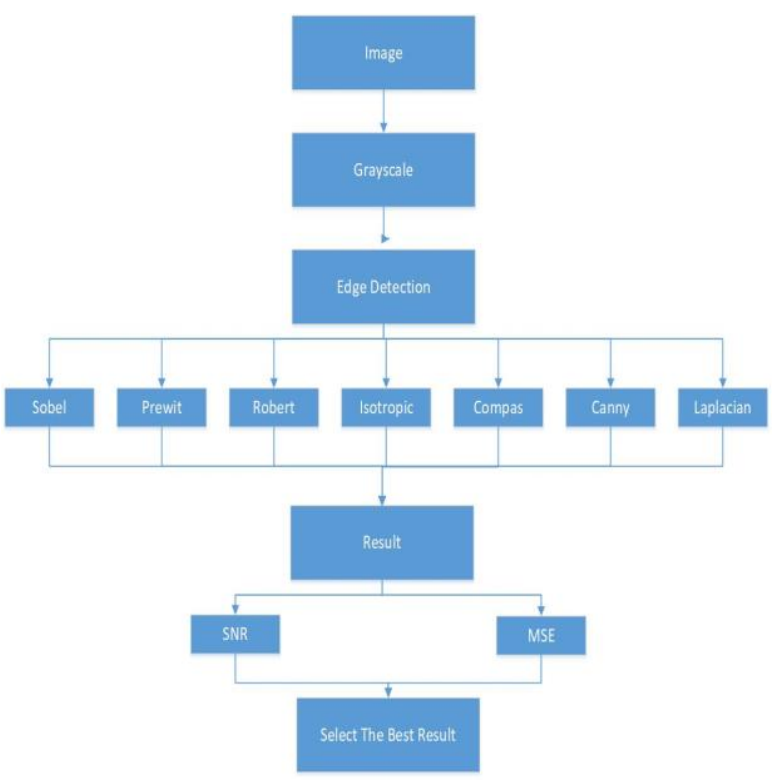

Gbr 1. Alur kerja penelitian

Dilihat pada gambar 1, mula-mula gambar akan diubah jadi grayscale. Setelah itu dilakukan proses edge detection terhadap gambar. Ada 8 algoritma edge detection yang digunakan, algoritma ini terbagi menjadi 2 yaitu orde satu meliputi Sobel, Prewit, Robert, Isotropic, Compas sedangkan orde dua meliputi Canny dan Laplacian. Selanjutnya hasil dari edge detection dihitung menggunakan SNR dan MSE. Nilai SNR dan MSE menjadi nilai tolak ukur penilaian terhadap kualitas dari hasil edge detection sehingga akan dibandingkan nilai SNR dan MSE dari semua algoritma.

\section{HASIL DAN PEMBAHASAN}

Dalam melakukan penelitian ini, diambil beberapa citra sebagai data eksperimen untuk membandingkan beberapa algoritma edge detection. Gambar di bawah menunjukkan beberapa contoh citra yang digunakan.

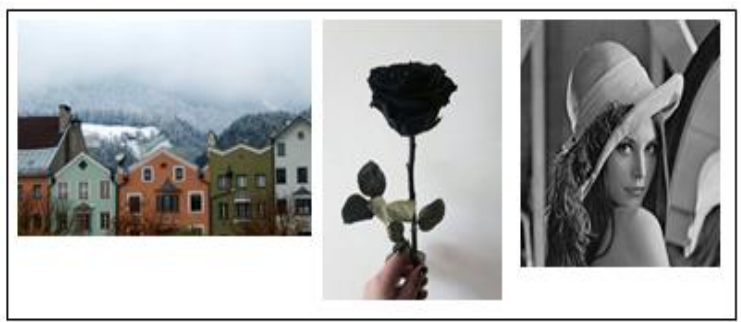

Gbr 2. Sampel gambar

Penelitian ini menggunakan aplikasi Matlab 2018b. Ketiga citra tersebut pertama-tama dikonversi menjadi GrayScale. Selanjutnya dilakukan edge detection terhadap ketiga citra di atas.

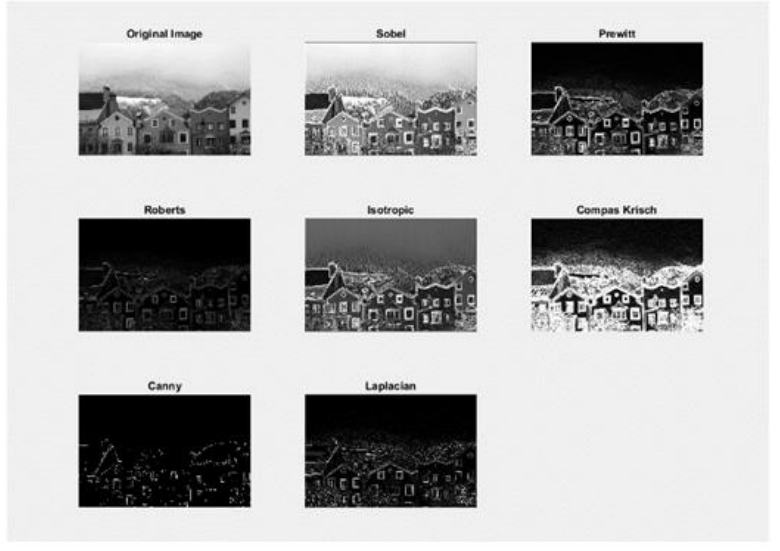

Gbr 3(a). Bangunan

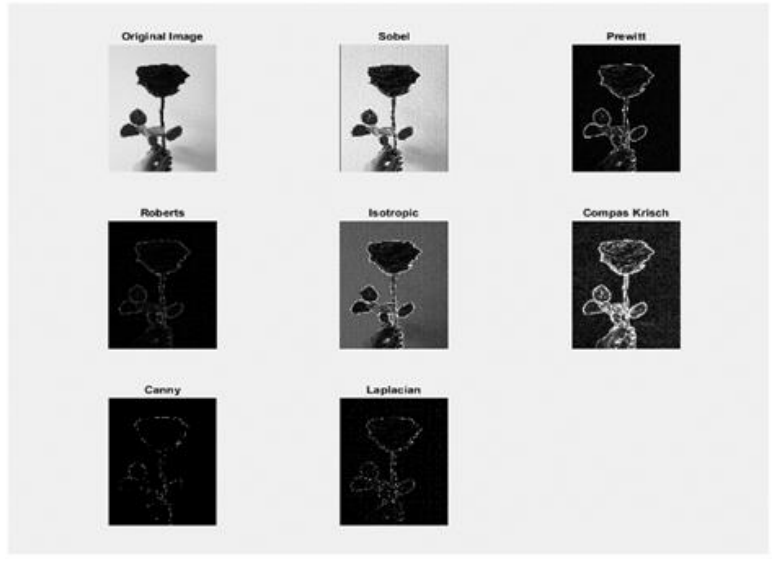

Gbr 3(b). Bunga
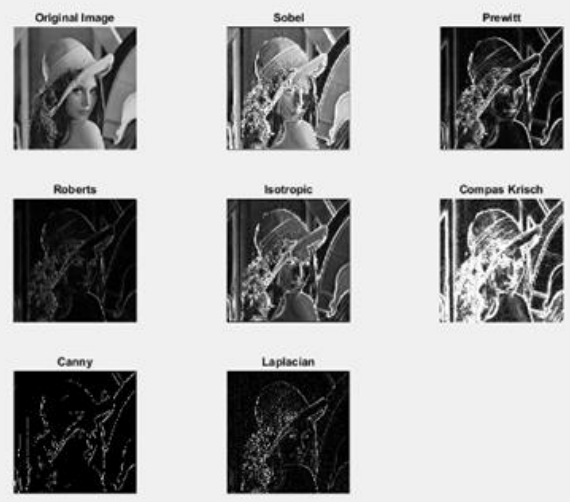

Gbr 3(c). Foto Wajah

Hasil dari metode deteksi tepi pada citra dapat dilihat pada Gambar 3. Gambar 3 memperlihatkan perubahan citra yang terjadi pada bagian tepi citra yang menjadi terang atau gelap. Gambar 3(a) berupa citra bangunan. Pada Gambar 3(b) berupa objek bunga dan Gambar 3(c) berupa objek manusia. Dari ketiga citra yang diujicoba, hasil edge detection dari metode sobel memperlihatkan hasil yang tampak jelas dan hampir mirip dengan citra asli akan tetapi hasil edge detection yang dihasilkan kurang memperlihatkan tepitepi gambar. Sedangkan metode prewitt, Roberts, 
canny dan laplacian lebih terlihat dikarenakan latar belakang hitam dan focus menghasilkan tepi-tepi objek dari sebuah citra. Untuk isotropic dan kompas kirsch lebih menggelapkan dan menerangkan citra sehingga hasil citra pada metode isotropic hanya terlihat seperti penggelapan citra sedangkan metode kompas membuat tepi-tepi citra sangat terang sehingga tidak tampak. Untuk menghitung hasil evaluasi kinerja (performance) deteksi tepi pada masing-masing skenario pre-processing digunakan perbandingan MSE dan PSNR. Langkah pertama deteksi tepi citra dilakukan dengan menerapkan semua usulan skenario. Langkah kedua adalah menghitung evaluasi menggunakan parameter PSNR dan MSE pada setiap hasil deteksi tepi dengan gambar awal yang sudah dikonversi ke grayscale.

\section{A. Mean Square Error (MSE)}

Mean Square Error (MSE) mengukur tingkat perbedaan kuadrat rata-rata. Nilai MSE didapatkan dari nilai selisih citra awal dengan citra hasil dengan posisi piksel yang sama. Semakin tinggi nilai MSE menunjukkan perbedaan besar antara citra awal dengan citra hasil. Perhitungan MSE menggunakan persamaan (8). Nilai $\mathrm{m}$ dan $\mathrm{n}$ adalah nilai ukuran panjang dan lebar citra. I(i,j) adalah citra awal dan $\mathrm{K}(\mathrm{i}, \mathrm{j})$ adalah citra hasil deteksi tepi.

$$
M S E=\frac{1}{m n} \sum_{i=0}^{m-1} \sum_{j=0}^{n-1}[I(i, j)-K(i, j)]^{2}
$$

Ketika citra diproses dan dilakukan restorasi, rekonstruksi dan kompresi, nilai MSE akan semakin berkurang. Tetapi, dalam deteksi tepi citra apabila MSE memiliki nilai yang tinggi menunjukkan bahwa lebih banyak tepi gambar yang terdeteksi serta mampu mendeteksi titik-titik tepi gambar yang lemah [12].

\section{B. Peak Signal to Noise Ratio (PSNR)}

Peak Signal to Noise Ratio (PSNR) digunakan untuk mengukur perbandingan nilai maksimum dari sinyal yang diukur dengan besarnya derau yang berpengaruh pada sinyal tersebut. PSNR biasanya menggunakan satuan desibel (dB). PSNR secara umum digunakan untuk menunjukkan nilai kualitas citra hasil rekonstruksi maupun hasil kompresi, sehingga semakin besar nilai PSNR menunjukkan semakin besar kualitas dari gambar yang dihasilkan. Tetapi, untuk kasus deteksi tepi nilai PSNR haruslah lebih rendah untuk mencapai hasil yang tepat. Perhitungan PSNR menggunakan persamaan (9), dimana $\mathrm{R}$ adalah nilai piksel maksimal yang mungkin dari suatu citra. Jika gambar 8-bit maka nilai $\mathrm{R}$ adalah 255 [12].

$$
P S N R=10 \log _{10}\left(\frac{R^{2}}{M S E}\right)
$$

\section{Hasil Perhitungan Evaluasi}

Perhitungan evaluasi dilakukan terhadap 3 buah citra. Masing-masing citra menghasilkan tujuh citra hasil deteksi tepi yang telah dilakukan. Evaluasi dihitung menggunakan MSE dan PSNR pada citra awal yang dibandingkan dengan citra hasil deteksi tepi. Hasil evaluasi ditunjukkan pada Tabel Evaluasi di bawah.

\begin{tabular}{|c|c|c|c|c|c|c|c|}
\hline \multirow{2}{*}{$\begin{array}{l}\text { N } \\
\text { o. }\end{array}$} & \multirow{2}{*}{$\begin{array}{c}\text { Edge } \\
\text { Detectio } \\
\mathbf{n}\end{array}$} & \multicolumn{2}{|c|}{ Citra 1} & \multicolumn{2}{|c|}{ Citra 2} & \multicolumn{2}{|c|}{ Citra 3} \\
\hline & & MSE & $\begin{array}{c}\text { PSN } \\
\text { R }\end{array}$ & MSE & $\begin{array}{c}\text { PSN } \\
\text { R }\end{array}$ & MSE & $\begin{array}{c}\text { PSN } \\
\text { R }\end{array}$ \\
\hline \multicolumn{8}{|c|}{ Orde 1} \\
\hline \multirow[t]{2}{*}{1.} & Sobel & 33,3 & 13,1 & 34,5 & 18,0 & 47,9 & 12,0 \\
\hline & & 95 & 6 & 34 & 9 & 3 & 6 \\
\hline \multirow[t]{2}{*}{2.} & Prewitt & 205 & & 225 , & & 184 & \\
\hline & & 35 & 4,34 & 49 & 2,89 & 04 & 8,46 \\
\hline \multirow[t]{2}{*}{3.} & Roberts & 238 & & 249 , & & 253, & \\
\hline & & 61 & 4,09 & 16 & 2,70 & 16 & 8,05 \\
\hline \multirow[t]{2}{*}{4.} & Isotropic & 188 & & 219, & & 166, & 10,5 \\
\hline & & 83 & 7,93 & 84 & 6,99 & 11 & 5 \\
\hline \multirow[t]{2}{*}{5.} & Compas & 149, & & 249, & & 253, & \\
\hline & (Kirsch) & 36 & 4,11 & 16 & 3,64 & 16 & 6,96 \\
\hline \multicolumn{8}{|c|}{ Orde 2} \\
\hline \multirow[t]{2}{*}{6.} & Canny & 246 , & & 249 , & & 253, & \\
\hline & & 95 & 3,67 & 16 & 2,55 & 16 & 7,02 \\
\hline \multirow[t]{2}{*}{7.} & Laplacian & 233 & & 241 , & & 230 , & \\
\hline & & 53 & 4,16 & 25 & 2,76 & 65 & 8,11 \\
\hline
\end{tabular}

TABEL I

Pada citra 1, sobel menunjukkan nilai MSE yang paling rendah, dan yang tertinggi adalah nilai pada canny. Canny mempunyai nilai MSE yang tinggi menunjukkan bahwa canny lebih banyak mendeteksi tepi gambar serta mampu mendeteksi titik-titik tepi gambar yang lemah dibandingkan metode yang lain. Untuk mendeteksi garis tepi yang tepat diperlukan nilai PSNR yang rendah. Pada citra 1 menunjukkan bahwa nilai PSNR dari canny yaitu sebesar 3,67 dB. Apabila dibandingkan dengan yang lain memiliki nilai yang paling rendah.

Pada citra 2, sobel tetap menunjukkan nilai MSE yang paling rendah tetapi yang tertinggi adalah nilai MSE dari 3 metode yaitu Roberts, Kompas dan Canny. Artinya ketiga metode ini hamper memiliki performa yang cukup bagus dalam melakukan edge detection. Untuk mendeteksi garis tepi yang tepat dilakukan lagi penilaian PSNR yang rendah. Pada citra 2 menunjukkan bahwa nilai PSNR dari canny yang terkecil yaitu sebesar $2,55 \mathrm{~dB}$, tetapi Roberts dan Kompas tidak memberikan nilai PSNR yang sama, masing-masing bernilai 2,70 dB dan 3,64 dB.

Untuk citra 3, sobel tetap menunjukkan nilai MSE yang paling rendah tetapi yang tertinggi adalah nilai MSE dari 3 metode yaitu Roberts, Kompas dan Canny 
dengan nilai 253,16. Sedangkan nilai PSNR yang terkecil kali ini diberikan oleh Kompas sebesar 6,96 dB sedangkan untuk Roberts dan canny masingmasing 7,02 db dan 8,05 walaupun hanya berbeda sedikit.

Page | 71

\section{KESIMPULAN}

Hasil evaluasi menunjukkan bahwa dari 3 citra yang di ujicoba metode canny mendapatkan 2 hasil terbaik dari ketiga citra dengan nilai MSE \& PSNR pada citra 1 dan 2 sebesar 246,95 \& 3,67 dB dan 249,16 \& 2,55 dB. Tetapi metode seperti Roberts dan Kompas (Kirsch) juga menghasilkan hasil yang tidak berbeda jauh dengan metode canny, sehingga kedua metode juga baik dalam melakukan edge detection karena nilai MSE maupun PSNR dari 3 citra ujicoba hanya berbeda sedikit dengan metode canny.

Diharapkan penelitian selanjutnya dapat meneliti tentang perbandingan edge detection dengan lebih banyak algoritma dan metode machine learning. Selain itu pula dapat mengklasifikasikan penggunaan edge detection yang efisien terhadap suatu citra berdasarkan beberapa kategori.

\section{REFERENSI}

[1] M. Hassaballah, A. A. Abdelmgeid, and H. A. Alshazly, Image Feature Detectors and Descriptors, vol. 630. 2016.

[2] D. Srivastava, R. Kohli, and S. Gupta, "Advances in Computer and Computational Sciences," vol. 554, pp. 211-228, 2018.

[3] O. Kobylin and V. Lyashenko, "Comparison of standard image edge detection techniques and of method based on wavelet transform," vol. 2, no. 8, pp. 572-580, 2014

[4] X. Zhang and W. Dahu, "Application of artificial intelligence algorithms in image processing," $J$. Vis. Commun. Image Represent., vol. 61, no. March, pp. 42-49, 2019.

[5] B. Wang, L. L. Chen, and Z. Y. Zhang, "A novel method on the edge detection of infrared image," Optik (Stuttg)., vol. 180, pp. 610-614, 2019.

[6] Y. Yitzhaky and E. Peli, "A method for objective edge detection evaluation and detector parameter selection," IEEE Trans. Pattern Anal. Mach. Intell., vol. 25, no. 8, pp. 1027-1033, 2003.

[7] Y. Li, S. Wang, Q. Tian, and X. Ding, "A survey of recent advances in visual feature detection," Neurocomputing, vol. 149, no. PB, pp. 736-751, 2015.

[8] G. Deng and Z. Liu, "Comparison and analysis for edge detection algorithms based on SQI image enhancement," Proc. 2015 27th Chinese Control Decis. Conf. CCDC 2015, pp. 36153617, 2015.

[9] S. R. Joshi and R. Koju, "Study and comparison of edge detection algorithms," Asian Himalayas Int. Conf. Internet, 2012.
[10] A. L. Schubert, D. Hagemann, A. Voss, and K. Bergmann, "Evaluating the model fit of diffusion models with the root mean square error of approximation," J. Math. Psychol., vol. 77, pp. 29-45, 2017.

[11] J. E. Figueroa-López and C. Mancini, "Optimum thresholding using mean and conditional mean squared error," J. Econom., vol. 208, no. 1, pp. 179-210, 2019.

[12] D. Poobathy and R. M. Chezian, "Edge Detection Operators: Peak Signal to Noise Ratio Based Comparison," Int. J. Image, Graph. Signal Process., vol. 6, no. 10, pp. 55-61, 2014.

[13] W. Luo, "Comparison for Edge Detection of Colony Images," J. Comput. Sci., vol. 6, no. 9, pp. 211-215, 2006.

[14] N. M. Zaitoun and M. J. Aqel, "Survey on Image Segmentation Techniques," Procedia Comput. Sci., vol. 65, no. Iccmit, pp. 797-806, 2015.

[15] G. T. Shrivakshan, "A Comparison of various Edge Detection Techniques used in Image Processing," vol. 9, no. 5, pp. 269-276, 2012.

[16] M. Juneja and P. S. Sandhu, "Performance Evaluation of Edge Detection Techniques for Images in Spatial Domain," vol. 1, no. 5, pp. 614-621, 2009.

[17] K. A. Panetta, E. J. Wharton, and S. S. Agaian, "Logarithmic edge detection with applications," J. Comput., vol. 3, no. 9, pp. 11-19, 2008.

[18] F. Samopa and A. Asano, "Hybrid Image Thresholding Method using Edge Detection," J. Comput. Sci., vol. 9, no. 4, pp. 292-299, 2009.

[19] Q. Ji and R. M. Haralick, "Efficient facet edge detection and quantitative performance evaluation," Pattern Recognit., vol. 35, no. 3, pp. 689-700, 2002.

[20] M. Sharifi, M. Fathy, and M. T. Mahmoudi, "A classified and comparative study of edge detection algorithms," Proc. - Int. Conf. Inf. Technol. Coding Comput. ITCC 2002, pp. 117120, 2002. 